individual therapy for the child (usually offered locally), parental counselling, six monthly group meetings for parents (held in London), assessment by our specialist paediatric endocrinologist and professional network meetings (held locally; di Ceglie, 1998). Alternatively, the specialist service may offer consultation only to professionals in the local child psychiatric team.

I agree with Dr White that the issues for which a consultation with a paediatric endocrinologist is sought before and after puberty can be different. It will be part of the assessment and ongoing management and therapy to determine which issues need the opinion and recommendation of the paediatric endocrinologist.

As many interventions with child, family and school are undertaken in parallel or at different stages it is crucial that there is good coordination among the various professionals involved and that timing of interventions is carefully considered. It is here that the resources and experience of a psychiatric specialist service are best employed.

Cohen-Kettenis P. T. \& van Goozen S. H. M. (1998) Pubertal delay as an ald in diagnosis and treatment of a transsexual adolescent. European Child \& Adolescent Psychiatry. 7, 246-248.

Di Cegue, D. (ed.) \& Freedman, D. (1998) A Stranger in My Own Body. London: Karnac.

DOMENICO DI Ceglie, Consultant Child \& Adolescent Psychiatrist, Adolescent Department, Tavistock Clinic, and Director, Gender Identity Development Unit, Portman Clinic, 8 Fitzjohn's Avenue, London NW3 5NA

\section{Women and old age poychiatry}

Sir: At the Faculty of Old Age Psychiatry residential conference in Cardiff (March 1999) there were 226 listed delegates of whom $43 \%$ were women. No session was chaired by a woman. No short paper was presented by a woman. Of 13 workshop presenters three $(23 \%)$ were women. and of 19 poster presenters eight were women (42\%). Two eminent women, Professor Elaine Murphy and Lady Sally Greengross, presented invited papers in the final session (50\% women).

One of the speakers in the short papers session commented on the absence of women and I feel it is important to reflect on this. The Faculty of Old Age Psychiatry should not be identified as a particular offender, as I suspect these findings are typical of College academic meetings. Old age psychiatry has a high proportion of women in consultant posts and in training posts. Why was our residential conference male dominated?

Are women trainees less likely to submit abstracts to academic meetings? Are women more likely to submit posters than oral papers: if so, why? Do women choose to investigate topics which are less attractive to or valued less by the men who select out abstracts for presentation? Are male trainees more likely to volunteer presentations? Should trainers be encouraging female trainees more actively? I have resolved to work harder on encouraging trainees to offer presentations. Should we do more?

SUSAN M. BENBOW, Consultant Psychiatrist lOld Age Psychiatry), Carisbrooke Resource Centre, Wenlock Way, Gorton, Manchester M12 5LF 